\title{
A unified in vitro evaluation for apatite-forming ability of bioactive glasses and their variants.
}

\author{
Anthony L. B. Maçon · Taek B. Kim · Esther M. Valliant · Katheryn Goetschius · \\ Richard K. Brow · Delbert E. Day · Alexander Hoppe · Aldo R. Boccaccini · Il-Yong \\ Kim - Chikara Ohtsuki - Tadashi Kokubo - Akiyoshi Osaka - Maria Vallet-Regí . \\ Daniel Arcos · Leandro Fraile · Antonio J. Salinas · Alexandra V. Teixeira · Yuliya \\ Vueva - Rui M. Almeida · Marta Miola - Chiara Vitale-Brovarone · Enrica Verné . \\ Wolfram Höland · Julian R. Jones
}

Received: date / Accepted: date

\begin{abstract}
The aim of this study was to propose and validate a new unified method for testing dissolution rates of bioactive glasses and their variants, and the formation of calcium phosphate layer formation on their surface, which is an indicator of bioactivity. At present, comparison in the literature is difficult as many groups use different testing protocols. An ISO standard covers the use of simulated body fluid on
\end{abstract}

Julian R. Jones (凶), Anthony L. B. Maçon, Taek B. Kim, Esther M. Valliant

Department of Materials, Imperial College London, London, SW7 2AZ

E-mail: julian.r.jones@imperial.ac.uk

Wolfram Höland

Vice-chairman of TC04 of ICG, Ivoclar Vivadent AG, Head of department, Inorganic Chemistry, Technical Fundamentals, R\&D, Benderestr.2 Li-9494 Liechtenstein, Principality of Liechtenstein

Richard K. Brow, Katheryn Goetschius, Delbert E. Day

Department of Materials Science \& Engineering, MS\&T, Rolla, MO 65409, USA

Aldo R. Boccaccini, Alexander Hoppe

Department of Materials, University of Erlangen-Nüremberg,91058 Erlangen, Germany

Chikara Ohtsuki, Il-Yong Kim

Nagoya University, Furo-cho, Chikusa-ku, Nagoya, Japan

Tadashi Kokubo

Chubu University, Matsumoto-cho, Kasugai-shi, Aichi, Japan

Akiyoshi Osaka

Graduate School of Natural Sciences and Technology, Okayama University, Tsushima, Okayama-shi 700-8530, Japan

Maria Vallet-Regí, Daniel Arcos, Leandro Fraile, Antonio J. Salinas Departamento de Quimica Inorganica y Bioinorganica - Universidad Complutense de Madrid - 28040 Madrid -Spain and CIBER-BBN

Alexandra V. Teixeira, Yuliya Vueva, Rui M. Almeida

Departamento de Engenharia Qumica e Biolgica / ICEMS Instituto Superior Tecnico / TULisbon, 1049-001 Lisbon, Portugal

Chiara Vitale-Brovarone, Marta Miola, Enrica Verné

Materials Science and Chemical Engineering, Politecnico di Torino, C.so Duca degli Abruzzi 24, 10129 Torino, Italy standard shape materials but it does not take into account that bioactive glasses can have very different specific surface areas, as for glass powders. Validation of the proposed modified test was through round robin testing and comparison to the ISO standard where appropriate. The proposed test uses fixed mass per solution volume ratio and agitated solution. The round robin study showed differences in hydroxyapatite nucleation on glasses of different composition and between glasses of the same composition but different particle size. The results were reproducible between research facilities. Researchers should use this method when testing new glasses, or their variants, to enable comparison between the literature in the future.

Keywords Bioactivity test $\cdot \mathrm{SBF} \cdot$ Hydroxycarbonated apatite - Bioglass - NovaBone · BonAlive · 13-93 .

Sr-bioglass $\cdot$ TheraGlass $\cdot$ Dissolution

\section{Introduction}

Bioactive glasses have huge potential as materials for bone regeneration. The original bioactive glass, developed by Larry Hench, had the $45 \mathrm{~S} 5$ composition $\left(46.1 \mathrm{~mol} \% \mathrm{SiO}_{2}, 26.9\right.$ $\left.\mathrm{mol} \% \mathrm{CaO}, 24.4 \mathrm{~mol} \% \mathrm{Na}_{2} \mathrm{O}, 2.6 \mathrm{~mol} \% \mathrm{P}_{2} \mathrm{O}_{5}\right)$ and was termed Bioglass ${ }^{\circledR}[1]$. In vivo studies showed it to bond to bone and stimulate more bone growth than particles of synthetic hydroxyapatite and apatite-wollastonite glass-ceramics [2]. The mechanism of bone bonding is through the formation of a surface layer of hydroxycarbonate apatite (HCA), which is similar to the mineral component of bone [3]. The HCA layer forms following cation exchange from the glass with protons from body fluid, which leaves a poorly connected silica rich layer [4]. Calcium phosphate precipitates on the silica rich layer and crystallises to form HCA [1]. The Bioglass composition is commercially available, in particu- 
late form, as a synthetic bone graft NovaBone ${ }^{T M}$ (NovaBone Products LLC, Jacksonville FL) and has been implanted in more than 1 million patients. A finer particulate form of the same glass is now also used to treat dental hypersensitivity by incorporation into toothpaste [5]. Since its development, there has been a lot of work investigating the effect of glass composition; morphology (particle versus monolith versus fibre versus scaffold) and glass type (melt versus sol-gel) on rate of dissolution and apatite formation in vitro. However many of the research articles describing the work present different protocols for testing the glass dissolution and apatite forming ability, making it difficult for the reader to make comparisons.

For this reason, an ISO standard has been proposed for the testing of the apatite forming ability of medical implants (ISO / FDIS 23317/, Implants for surgery In vitro evaluation for apatite-forming ability of implant materials) [6]. However this test was designed for testing bioceramic or glass-ceramic coatings on metal substrates or for monolithic (disc) shaped samples. It does not translate well to powder or porous bioactive glasses. There are two main reasons for this: i) the ISO test fixes the surface area to solution volume ratio when comparing samples; ii) the test is static. Keeping surface area constant allows comparison between samples of different compositions but does not allow comparison between samples of the same composition but different morphologies. Surgeons are likely to use such materials for filling a bone defect of a certain volume, so fixing surface area would not be suitable for the development of bioactive glass fibres and porous scaffolds [7, 8, 9, 10]. Sol-gel glasses also have specific surface areas several orders of magnitude higher than melt-derived glasses, for the same particle size, due to their inherent nanoporosity. Therefore fixing surface area to compare dissolution of a sol-gel and a melt-derived glass would not even be possible, and would not be a valid test.

The aim is not to develop a method for predicting whether materials will form a bond with bone. As reported previously, in vitro conditions cannot match those in vivo, and a simulated body fluid does not exist that exactly matches those of the human body [11]. Instead, the aim is to develop a facile test that can be used in most research laboratories around the world and allow comparison of dissolution rates and apatite nucleation. The test is a modification of the ISO standard, which uses simulated body fluid [12]. The proposed test agreed upon by Technical Committee 4 (TC04) of the International Commission on Glass (ICG) and will be referred to here as the TC04 method. This test was validated through a round robin study in eight different laboratories in seven countries to ensure reproducibility and to compare to the ISO standard. High purity, commercial glasses were used that were produced under Good Manufacturing Practice (GMP), 5 melt and 1 sol-gel derived. NovaBone (NB) is the commercial form of Bioglass, which has a broad particle size distribution. BonAlive ${ }^{T M}$ (BA, Vivoxid, Turku, Finland) is another melt-derived particulate with a different ratio of its component oxides [13]. 13-93 is a composition that was originally was designed for fibre drawing, as it is difficult to pull Bioglass fibres without the glass crystallising [14]. More recently it has been used to produce scaffolds for bone regneration [7]. StonBone has a similar composition to Bioglass, except that some of the calcium was substituted with strontium [15]. TheraGlass (TheraGlass Ltd., London, UK) is a binary sol-gel derived glass [16]. Details of the glass compositions are given in Table 1.

\section{Materials and Methods}

\subsection{The bioactive glasses}

Commercial samples of bioactive glasses were used to ensure all groups had reproducible samples. All the different elemental compositions are details in Table 1. BonAlive (Vivoxid, Turku, Finland) has a particle size range of $45-90 \mu \mathrm{m}$ (BA). Mo-Sci (Rolla, MO) kindly produced 45S5 Bioglass (BG) and 13-93 to the same particle size range. Sr-Bioglass (Sr-BG) of the same particle size range was provided by RepRegen Ltd. (London, UK). A sol-gel derived bioactive glass TheraGlass (TG) was provided by MedCell Bioscience. The particle sizing was carried out by sieving. Bioglass 45S5 is marketed as NovaBone (NB) with a specified particle size range of $90-710 \mu \mathrm{m}$ provided by Novabone LLC (Jacksonville, FL).

Table 1 Elemental composition of the bioactive glasses tested given in mol\%. $\dagger$ Novabone and 45S5 Bioglass have the same elemental composition but different particle sizes

\begin{tabular}{llllllll}
\hline Glass & $\mathrm{SiO}_{2}$ & $\mathrm{CaO}$ & $\mathrm{Na}_{2} \mathrm{O}$ & $\mathrm{P}_{2} \mathrm{O}_{5}$ & $\mathrm{SrO}$ & $\mathrm{K}_{2} \mathrm{O}$ & $\mathrm{MgO}$ \\
\hline $45 \mathrm{~S}^{\dagger}$ & 46.1 & 26.9 & 24.4 & 2.6 & - & - & - \\
$13-93$ & 54.6 & 22.1 & 6.0 & 1.7 & - & 7.9 & 7.7 \\
$\mathrm{BA}$ & 53.8 & 21.9 & 22.7 & 1.7 & - & - & - \\
$\mathrm{Sr}-\mathrm{BG}$ & 44.5 & 21.5 & 27.2 & 4.4 & 2.4 & - & - \\
$\mathrm{TG}$ & 70.0 & 30.0 & - & - & - & - & - \\
\hline
\end{tabular}

\subsection{Pre-test characterization}

Surface area and density measurement : Nitrogen sorption was used to estimate the surface area of the glass powders (Autosorb AS6, QuantaChrome). In order to remove any trace of moisture, samples were degassed at $150^{\circ} \mathrm{C}$ for $8 \mathrm{~h}$ before analysis (Degasser, Quantachrome). Specific surface areas were calculated by fitting the first seven points (relative pressures of $0.05-0.3$ ) of the adsorption branch of the 
isotherm to the BET equation [17]. Skeletal density was determined by helium pycnometry (Ultrapycnometer 1000, QuantaChrome) on glasses, with the use of a known mass of powder previously dried at $80^{\circ} \mathrm{C}$ for $24 \mathrm{~h}$.

Particle size analysis: Particle sizes were measured using a laser diffraction (Malvern Mastersizer 2000 equipped with a Hydro 2000 SM dispersion unit). The volume average particle diameters $\mathrm{D}$ quoted are obtained from at least 5 repeat runs. $d(0,5)$ is the diameter under which $50 \%$ of the particles fall.

\subsection{Bioactivity tests}

Simulated body fluid preparation: Simulated body fluid (S BF) was prepared according to Kokubo's method [12]. Reagents (Table 2) were provided by Sigma-Aldrich UK and used as received without further purification. To produce 1 $\mathrm{L}$ of SBF, $700 \mathrm{~mL}$ of deionized (DI) water was placed in a $1 \mathrm{~L}$ polypropylene beaker and set at $37^{\circ} \mathrm{C} \pm 1.0^{\circ} \mathrm{C}$ in a water bath. The solution was continuously stirred throughout. The reagents were slowly added to the DI water in the order given in Table 2 with an accuracy of $\pm 0.5 \mathrm{mg}$. The $\mathrm{pH}$ was monitored to avoid any rapid increase, which would cause precipitation. Once the reagents were mixed, the SBF was transferred to a $1 \mathrm{~L}$ volumetric flask and filled to the mark with DI water once cooled at RT. SBF was stored at $37^{\circ} \mathrm{C}$ and used within 2 days. The $\mathrm{pH}$ was adjusted to 7.4 before use at $37^{\circ} \mathrm{C}$.

Table 2 Reagents used for preparing SBF solution

\begin{tabular}{clcl}
\hline Order & Reagent & Amount $\left(\mathrm{g} . \mathrm{L}^{-1}\right)$ & CAS number \\
\hline 1 & $\mathrm{NaCl}$ & 8.035 & $7647-14-5$ \\
2 & $\mathrm{NaHCO}_{3}$ & 0.355 & $144-55-8$ \\
3 & $\mathrm{KCl}$ & 0.225 & $7447-40-7$ \\
4 & $\mathrm{~K}_{2} \mathrm{HPO}_{4} \cdot 3 \mathrm{H}_{2} \mathrm{O}$ & 0.231 & $16788-57-1$ \\
5 & $\mathrm{MgCL}_{2} \cdot 6 \mathrm{H}_{2} \mathrm{O}$ & 0.311 & $7791-18-6$ \\
6 & $\mathrm{HCL} 1 \mathrm{M}_{7}$ & $38 \mathrm{~mL}$ & $7647-01-0$ \\
7 & $\mathrm{CaCl}_{2} \cdot 2 \mathrm{H}_{2} \mathrm{O}$ & 0.386 & $10035-04-8$ \\
8 & $\mathrm{NaSO}_{4}$ & 0.072 & $7757-82-6$ \\
9 & $\mathrm{Tris}$ & 6.118 & $77-86-1$ \\
\hline
\end{tabular}

TC04 method: Bioactivity of powders based on concentration: Bioactive glass powders were immersed in SBF using a ratio of $75 \mathrm{mg}$ glass to $50 \mathrm{~mL}$ SBF in an airtight polyethylene container. Dissolution vessels were placed in an incubating orbital shaker held at $37^{\circ} \mathrm{C}$, agitated at $120 \mathrm{rpm}$. The $\mathrm{pH}$ and temperature of the media was verified before use. The samples were incubated for 7 different time points: $4 \mathrm{~h}$, 8 h, 24 h, 72 h, 1 week, 2 weeks, 3 weeks and 4 weeks. At the end of each time period, the sample was removed from the incubator and the solids were collected by filtration (particle retention $513 \mu \mathrm{m}$ ). The powder was immediately washed with DI and subsequently with acetone to terminate any reaction. Each sample was run in triplicate. The filtered solution was collected to determine the ion concentrations using an induced coupled plasma (ICP) analysis; the pH of the solution was also measured. The same protocol was applied to SBF alone as a control.

ISO / FDIS 23317: Bioactivity of powders based on surface area: Bioactive glass powders were immersed in SBF using a fixed volume to surface area ratio: $\mathrm{V}_{S B F}=100 * \mathrm{~S}_{a, \text { glass }}$ where $\mathrm{V}_{S B F}$ is the volume of SBF used and $\mathrm{S}_{a, g l a s s}$ the apparent surface area of the specimen. Here, the mass of glass particles used for each composition was calculated for 100 $\mathrm{mL}$ of SBF. The rest of the protocol was the same as previous test except that samples were not agitated. Each sample was run in triplicate. This ISO standard was designed for solid disc shaped samples, so discs of 13-93 composition were also tested.

\subsection{Post-test characterization}

Inductive coupled plasma - atomic emission spectroscopy: Concentrations in solution were measured with a Thermo Scientific iCAP 6300 Duo inductive coupled plasma - optical emission spectrometer (ICP-AES) with auto sampler. Sample solutions were prepared by diluting the samples by a factor of 10 with analytical grade $2 \mathrm{M} \mathrm{HNO}_{3}$. Mixed standards of silicon, phosphorous, calcium, sodium and potassium were prepared at $0,2,5,20$ and $40 \mu \mathrm{g} \cdot \mathrm{mL}^{-1}$ for the calibration curve. Silicon and phosphorous were measured in the axial direction of the plasma flame whereas calcium, sodium and potassium were measured in the radial direction.

Fourier transform infrared spectroscopy: $\mathrm{KBr}$ pellets containing bioactive glass powder were prepared under 8 tons of pressure at a ratio of $2 \mathrm{wt} \%$ of sample to $\mathrm{KBr}$. Fourier transform infrared spectroscopy (FTIR) was performed using a Thermo Nicolet Nexus 670 FTIR purged with nitrogen in transmission mode with a spectral resolution of $2 \mathrm{~cm}^{-1}$ from 4000 to $400 \mathrm{~cm}^{-1}$. Spectra were collected as mean of 32 scans and plotted as adsorption.

$X$-Ray diffraction : X-ray diffraction (XRD) patterns of glasses before and after immersion in SBF were recorded using a Panalytical Xpert Pro MPD. The radiation source was a Ni filtered $\mathrm{Cu} \kappa_{\alpha}$. Diffraction was measured continuously from 6 to $70^{\circ} 2 \theta$, with a step size of $0.026^{\circ}$ and a time per step of 100 seconds. 
Table 3 Size and surface analysis of bioactive glass particles. The estimated surface area was calculated using Estimated SSA $=\frac{3}{\rho_{s} * r}$, where $\mathrm{r}$ is particle radius and $\rho_{s}$ the skeletal density. The last column represents the mass of glass used for the ISO standard.

\begin{tabular}{|c|c|c|c|c|c|c|c|c|}
\hline Glass & $\begin{array}{l}\text { Sample } \\
\text { code }\end{array}$ & $\begin{array}{c}\text { Network } \\
\text { connectivity (NC) }\end{array}$ & \multicolumn{2}{|l|}{ Particle size } & $\begin{array}{c}\rho_{s}, \text { Density } \\
\left(\text { g.cm }^{-3}\right)\end{array}$ & $\begin{array}{l}\text { Estimated SSA } \\
\qquad\left(\mathrm{m}^{2} \cdot \mathrm{g}^{-1}\right)\end{array}$ & $\begin{array}{l}\text { BET SSA } \\
\left(\mathrm{m}^{2} \cdot \mathrm{g}^{-1}\right)\end{array}$ & $\begin{array}{c}\text { Mass required } \\
(\mathrm{mg} / 100 \mathrm{~mL})\end{array}$ \\
\hline Bioglass & BG & 2.1 & $74.4 \pm 1.0$ & $76.1 \pm 1.2$ & 2.71 & 0.029 & 0.24 & 4.17 \\
\hline NovaBone & NB & 2.1 & $22.5 \pm 2.1$ & $87.6 \pm 7.2$ & 2.72 & 0.025 & 0.36 & 2.78 \\
\hline $13-93$ & $13-93$ & 2.6 & $76.5 \pm 1.4$ & $79.9 \pm 1.45$ & 2.76 & 0.027 & 0.09 & 11.11 \\
\hline BonAlive & BA & 2.5 & $73.4 \pm 0.3$ & $77.5 \pm 0.4$ & 2.66 & 0.028 & 0.21 & 4.76 \\
\hline Sr-Bioglass & Sr-BG & 2.3 & $76.8 \pm 0.4$ & $81.1 \pm 0.6$ & 2.81 & 0.027 & 0.20 & 5.0 \\
\hline Theraglass & TG & - & $42.9 \pm 0.2$ & $45.5 \pm 0.1$ & 2.71 & 0.047 & 78.02 & 0.012 \\
\hline
\end{tabular}

Scanning electron microscopy : Field emission gun scanning electron microscopy (FEG-SEM) was performed on a JEOL 7100 using a gun voltage of $15 \mathrm{kV}$ and a working distance of $10 \mathrm{~mm}$. Samples were mounted on double sided carbon tape and coated with gold.

Statistics: Where required, sample sets were statistically tested against a null hypothesis using a t-test implemented on Matlab R2013b (function $t$-test2). Samples were considered pai-red with equal size and unequal variance. The level of statistical significance was fixed at 0.05 .

\section{Results and Discussion}

\subsection{Pre-test characterisation}

Each company sized their particles by sieving, using sieves of $90 \mu \mathrm{m}$ and $45 \mu \mathrm{m}$, with the exception of NovaBone, who used sieves of $90 \mu \mathrm{m}$ and $710 \mu \mathrm{m}$. As dissolution is dependent on surface area, it was important to measure the actual particle size distributions (refer to supplementary figure)[18]. Table 3 shows the $d_{50}$ which is the diameter under which $50 \%$ of the particles fall and D which is an arithmetic volume average of the particle equivalent diameters. The $d_{50}$ and D values were similar (within $5 \mu \mathrm{m}$ ) for all powders, except NovaBone. This means that all glasses except NovaBone had Gaussian-like particle size distributions. NovaBone had a trimodal distribution with modes at $0.4 \mu \mathrm{m}$, $11.5 \mu \mathrm{m}$ and $208.9 \mu \mathrm{m}$. All melt-derived powders with the specified ranges of $45-90 \mu \mathrm{m}$ also had similar values $\mathrm{d}_{50}$ and D values (73-87 $\mu \mathrm{m})$. TheraGlass particles were smaller (D of $45.5 \mu \mathrm{m}$ ), which is likely to be due to their inherent nanoporosity, making grinding easier.

The skeletal density, $\rho_{s}$, of all the glasses where similar at approximately $2.7 \mathrm{gcm}^{-3}$ (see Table 3 ).

Limitation of ISO / FDIS 23317 for bioactive glasses: This method was designed only for solid, regular geometric shaped samples, such as dics or tiles and was never designed for glass powders or porous materials. This leads to the first problem with carrying out the bioactivity testing with the
ISO standard; the measurement of the surface area of the glass powders. Consistent measurement of specific surface area (SSA) for glass particles exceeding $30 \mu \mathrm{m}$ in size is difficult. Two methods were used: i) combination of the particle size distribution and the density of the particles; ii) gas adsorption using the BET method [19]. The first method incorrectly assumes that all particles were spherical, underestimating the surface area due to the angularity of ground glass powders (Table 3 ). It also did not take into account the intrinsic nanoporosity of the sol-gel derived glass (TG). Nitrogen sorption did take the porosity into account and the data for TG were in good agreement with the literature [20]. However, the BET SSA values for the melt derived glasses were small, ranging from 0.20 to $0.36 \mathrm{~m}^{2} . \mathrm{g}^{-1}$, which are below the accurate detection limits of $1 \mathrm{~m}^{2} \cdot \mathrm{g}^{-1}$ [21, 22]. Once SSA was obtained, the quantity of glass needed to perform the ISO standard in $100 \mathrm{~mL}$ of SBF was calculated using BET SSA (Table 3). Values for the melt-derived glasses varied from 2.78 to $5 \mathrm{mg}$ for $100 \mathrm{~mL}$ of SBF. However, for the sol-gel derived glass the amount of glass was impractical (0.012 mg per $100 \mathrm{~mL}$ of SBF). Therefore, only the meltderived glasses were tested with the ISO standard.

3.2 Bioactivity of commercially available bioactive glasses.

The TC04 method fixes the mass of glass in SBF was compared to the ISO test, which used a consistent surface area.

For both tests, the concentration of silicon, calcium and phosphorus and the $\mathrm{pH}$ value varied over the length of the test compared with SBF alone (Figure 1). The rise in $\mathrm{pH}$ was due to the cation exchange, predominantly of $\mathrm{Na}^{+}$and $\mathrm{Ca}^{2+}$ from the glasses with protons from the solution [4]. Using the TC04 method, the $\mathrm{pH}$ level after 4 weeks increased with the amount of cations present originally in the glass composition. There was no such pattern observed with the ISO standard. This is due to the low mass of melt-derived glass powder in the ISO standard test, releasing such a low concentration of cations that it did not disturb the buffering capacity of SBF. To test this hypothesis, a disc of 13-93 glass was tested by the ISO test. The SSA of the disc was 0.00465 $\mathrm{m}^{2} \cdot \mathrm{g}^{-1}$, so the $0.082 \mathrm{~g}$ was immersed in $64 \mathrm{~mL}$ of SBF. 

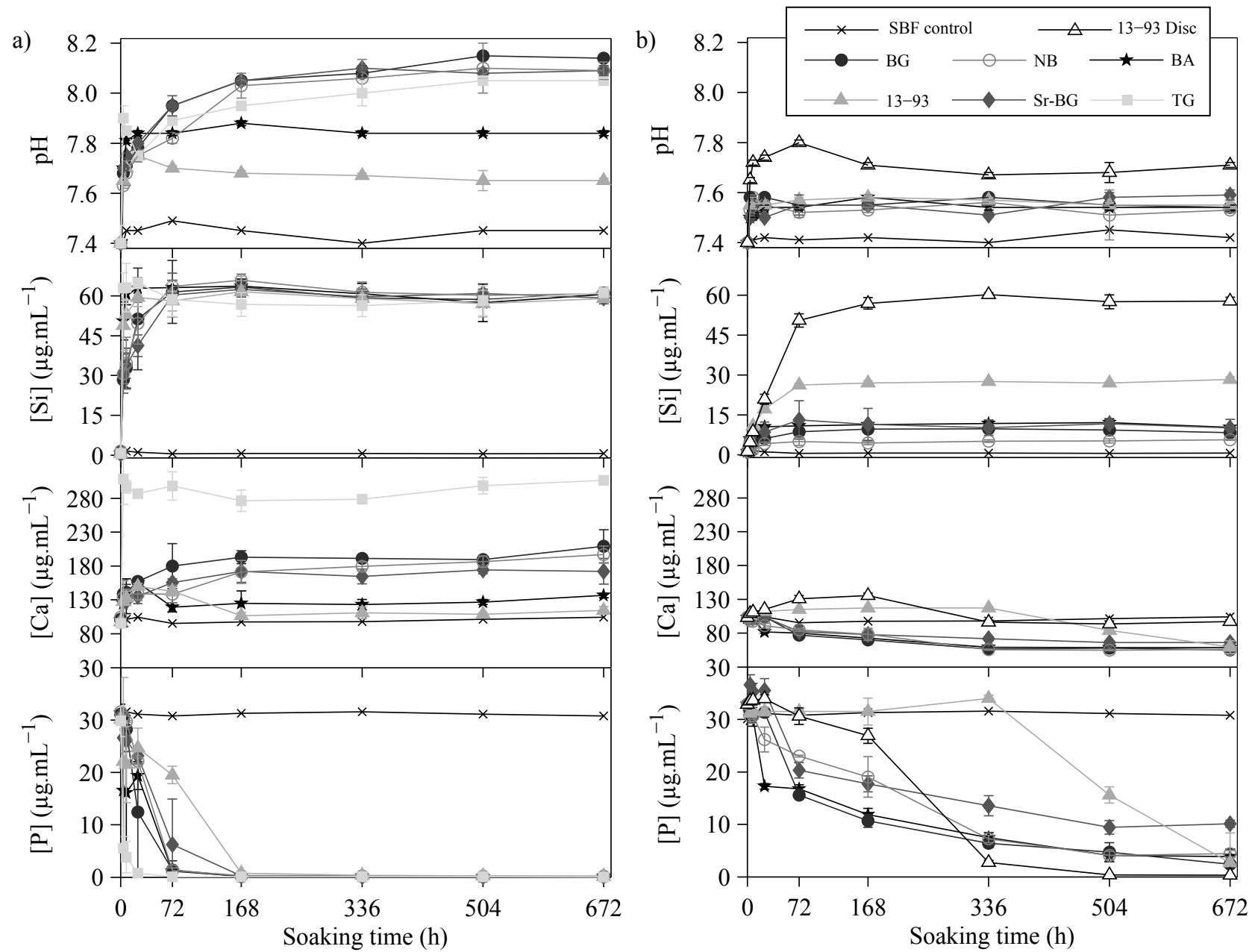

Fig. 1 Dissolution profiles as a function of time for bioactive glasses using a) the TC04 method and b) the ISO standard (Could not be used for the sol-gel glass TG).

This led to a $\mathrm{pH}$ of 7.71 at 4 weeks, with [Ca] of $97.0 \pm 2.7$ $\mu \mathrm{g} . \mathrm{mL}^{-1}$, due the higher mass of glass. The silica $(57.6 \pm 1.4$ $\mu \mathrm{g} . \mathrm{mL}^{-1}$ ) and calcium release from the disc were similar to that of the powders in the TC04 method. The difference was the phosphorous depletion in the SBF was slower for the disc in the ISO standard compared to the powder in the TC04 method, as the surface area of the powder was greater, which is likely to enhance HCA formation.

In the $\mathrm{TC} 04$ test, the $\mathrm{pH}$ rise for $\mathrm{TG}$ was in the same order as that for NB after 4 weeks of dissolution $(\mathrm{pH}=8.05$ and 8.09 respectively, $\mathrm{p}>0.5$ ). However, TG only contains $30 \mathrm{~mol} \%$ of $\mathrm{CaO}$ (compared to $26.9 \mathrm{~mol} \%$ for NB), which indicated that the intrinsic nanoporosity enhanced its dissolution [23, 24]. In addition sol-gel glasses have lower network connectivity (number of bridging oxygen bonds per silicon atom) than their nominal composition suggests, due to the presence of $\mathrm{Si}-\mathrm{OH}$ groups, where $\mathrm{H}^{+}$ions act as additional network modifiers [20].

The soluble silica release profiles for all compositions showed an increase in the concentration, following a neg- ative exponential trend, levelling off after 3 days of dissolution. However, the [Si] profiles differed between the two tests. In the TC04 test, the soluble silica released at different rates depending on glass compositions (see Supplementary Table 1), but the final concentration after 4 weeks was statically equivalent among all glasses $\left([\mathrm{Si}]_{4 w k s}=60.2 \mu \mathrm{g} \cdot \mathrm{mL}^{-1}\right.$, $\mathrm{p}>0.25$ ). However, the amount of soluble silica released using the ISO standard was directly proportional to the initial mass of glass (Supplementary Figure II). This would falsely imply that 13-93 degraded faster than NB as both glasses had theoretically the same surface exposed to the media. However, there was a greater mass of 13-93 initially immersed in the SBF $(11.11 \mathrm{mg})$ than NB $(2.78 \mathrm{mg})$, due to the difference in the measured surface area between 13-93 and NB. Due to the inaccuracy of the BET method for these particles, more 13-93 glass was immersed in the SBF, causing the absolute amount of silica release to be higher. 13-93 is known to have a higher network connectivity than 45S5 making the glass more resistant to degradation (Table 3)[25]. 
The concentration of calcium and phosphorus in SBF were also monitored as a function of time. A decrease in their level is usually considered as a good indicator of bioactivity [18]. SBF contains approximately $90 \mu \mathrm{g} \cdot \mathrm{mL}^{-1}$ of calcium ions and $30 \mu \mathrm{g} . \mathrm{mL}^{-1}$ of phosphorus. The release of calcium followed the trend of the silica release over the first day of dissolution when using the TC04 method, showing a homogeneous degradation of the glass. Subsequently, for glasses with the lower amounts of calcium in their composition (13-93 and BA) calcium concentration in SBF decreased, whereas all the other compositions levelled off. For instance, despite having released the same amount of calcium within $24 \mathrm{~h}\left(155 \mu \mathrm{g} . \mathrm{mL}^{-1}, \mathrm{p}>0.15\right)$, [Ca] for BA (20 $\mathrm{mol} \% \mathrm{CaO}$ ) dropped to $123 \pm 7.6 \mu \mathrm{g} . \mathrm{mL}^{-1}$ at 4 weeks whereas [Ca] for $\mathrm{BG}(26.9 \mathrm{~mol} \% \mathrm{CaO})$ increased to $209.3 \pm 24.4$ $\mu \mathrm{g} \cdot \mathrm{mL}^{-1}$. The concentration of phosphorus decreased for all compositions regardless of the method used. However, the TC04 method exhibited a more defined and more rapid decrease in $[\mathrm{P}]$. As an example, 13-93 had an immediate decrease in [P] approaching $0.5 \mu \mathrm{g} \cdot \mathrm{mL}^{-1}$ at 1 week, using the TC04 method, whereas [P] started to decline only after 2 weeks using the ISO standard method. Again, this could be due to a lower mass of glass present in the ISO standard, but could also be due to the agitation in the TC04 test [26].

\subsection{Post-test surface characterisation}

Apatite nucleates on the surface of the different bioactive glasses, all the participants of this round robin test were asked to investigate surface chemistry changes using FTIR and XRD. Due to the small mass of glass powder used in the proposed standard, only FTIR analysis was carried out on these solids, which are given in supplementary information (Figure SIII). Figure 2 shows the FTIR spectra obtained after 4 weeks immersion in SBF (TC04 method). The mechanism of apatite formation is known to involve silicarich layer formation at the glass surface, following cation exchange, containing $\mathrm{Si}-\mathrm{OH}$ groups that act as nucleation sites for amorphous calcium-phosphate[27, 28]. The local $\mathrm{pH}$ increase promotes calcium-phosphate $(\mathrm{Ca}-\mathrm{P})$ crystallisation where the tetrahedral $\mathrm{PO}_{4}^{-3}$ exhibits sharp IR absorptions at 565 and $605 \mathrm{~cm}^{-1}$, characteristic of P-O bending, and at $1030 \mathrm{~cm}^{-1}$, characteristic of P-O stretching[29, 30]. Spectra collected from BG showed the P-O bending vibration bands after $24 \mathrm{~h}$ of immersion in SBF (Figure 2-a). Other bands characteristic of carbonate group, $\mathrm{CO}_{3}^{-2}$, were detected at $1460 \mathrm{~cm}^{-1}, 1420 \mathrm{~cm}^{-1}$ and $875 \mathrm{~cm}^{-1}$, which is a sign of B-type carbonated apatite precipitation : $\mathrm{Ca} 9\left(\mathrm{HPO}_{4}\right)_{0.5}$ $\left(\mathrm{CO}_{3}\right)_{0.5}\left(\mathrm{PO}_{4}\right)_{5} \mathrm{OH}(\mathrm{HCA})$, mimicking bone like apatite[3, 31]. The precipitation of pure hydroxyapatite (HA) is less likely to happen in SBF as it is saturated with respect of slightly carbonated apatite, where the orthophosphates are substituted by carbonates in the crystal lattice[32]. Only TG was found to nucleate $\mathrm{Ca}-\mathrm{P}$ crystal at a similar (fast) rate to BG. Sol-gel derived glasses, due to their higher surface area, the abundance of $\mathrm{OH}$ groups and low network connectivity are better inducer of nucleation than melt derived glasses of similar compositions[23, 28]. All the other glasses were found to nucleate apatite slower (Figure 2-b). Time points at which apatite did nucleate on the glasses is discussed the results of the round robin study section below. Something to consider with FTIR spectra is that the $\mathrm{P}-\mathrm{O}$ bending bands are not characteristic to HA or HCA, they indicate the presence of orthophosphate lattices [33].

Therefore, to confirm the nature of the newly crystalline phase formed at the surface the different glasses, X-ray diffraction was carried out as shown in Figure 3. XRD results were in good agreement with FTIR with crystalline peaks observed at $24 \mathrm{~h}$ for BG, confirming abundant HCA formation on the surface of the glass, with sharp peak at $2 \theta \approx$ $26^{\circ}$ and $32^{\circ}$ and a positive correlation of the other peaks with external reference (ICSD 01-084-1998). The bioactivity of BG reported here was in agreement with literature[18]. However, a mixture of HCA and calcite (calcium carbonate, ICSD 52151) was found on the surface of TheraGlass, highlighting the importance and the complementarity of XRD with FTIR. This observation had already been made by Martinez et. al. who investigated the bioactivity of $\mathrm{CaO}-\mathrm{SiO}_{2}$ binary sol-gel glasses[34]. For their bioactivity test, disks were produce of the dimension recommended by the ISO method, overlooking the higher surface area of the sol-gel glass[12]. Interestingly, crystalline phases were sharper and more defined using the $\mathrm{TC} 04$ proposed here, due to the increase in exposed surface to the media between disk and powder. Finally, change in morphology due to the dissolution and precipitation of crystal on the different glasses was analysed by electron microscopy. The surfaces of the bioactive glasses were found to be smooth and dense before immersion in SBF. However, large needle-like structure characteristic to HA were found to cover almost the entire surface of BG and TG after $24 \mathrm{~h}$ of immersion [35]. At the same time point, NB was found with a mixed of amorphous calcium phosphate and HCA, corroborating data obtained by XRD and FTIR.

\subsection{Round robin outcomes}

Figure 5 summarises the results obtained across the 8 institutions that participated in this round robin test. Grey shading shows HCA was detected by FTIR/XRD, with the fraction of participants obtaining the same result given in parentheses. The $\dagger$ symbol indicates where the HCA was appeared at the same time point in the TC04 and ISO test, i.e. where the tests agreed according to post test surface analysis. Note that only 6 out of 8 institutions investigated the bioactivity of BA. Using the TC04 method, the direct effect of the particle size on the bioactivity could be seen. BG, which has a 
a)

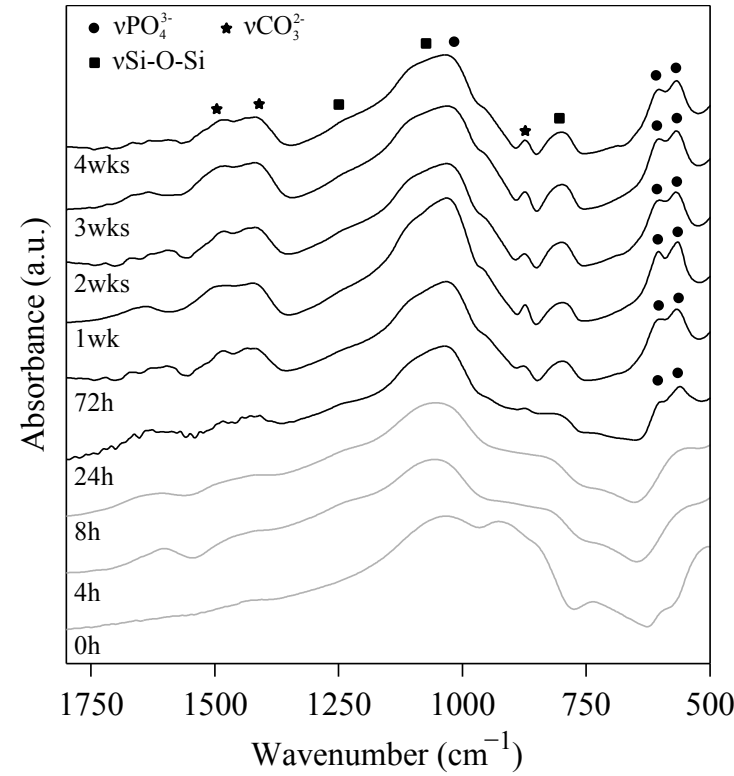

b)

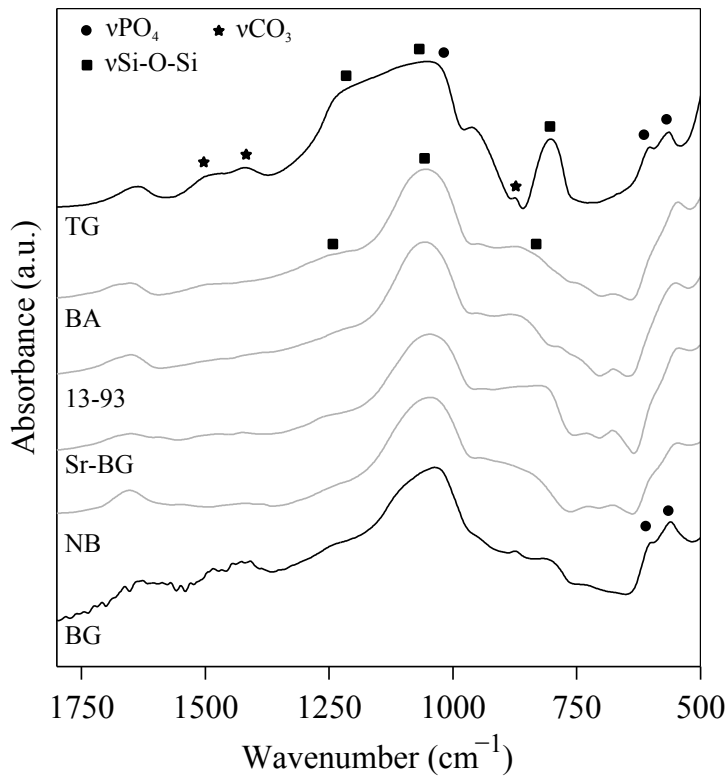

Fig. 2 FTIR spectra of a) Bioglass (BG, 45-90 $\mu \mathrm{m}$ ) from 0 to 4 weeks immersion in SBF following the TC04 method and b) for all glass compositions after $24 \mathrm{~h}$ immersion in SBF, which was the time point at which P-O bands were first detected for BG.

a)

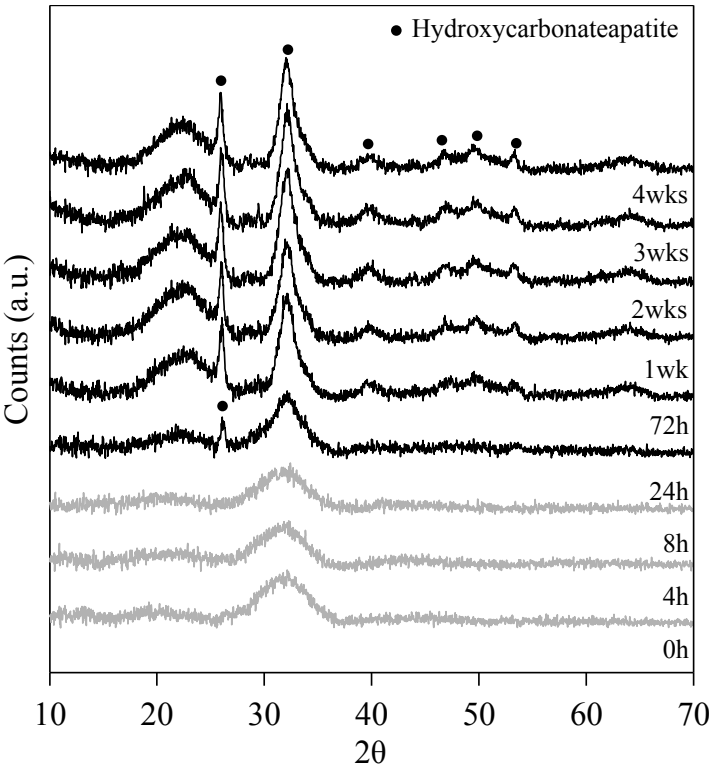

b)

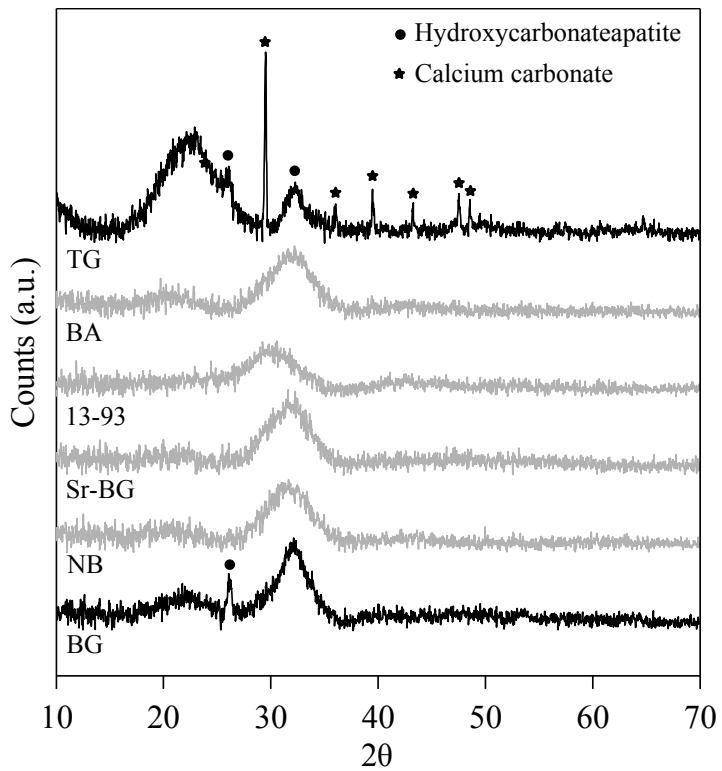

Fig. 3 XRD spectra of a) Bioglass (BG, $45-90 \mu \mathrm{m}$ ) from 0 to 4 weeks immersion in SBF following the TC04 method and b) for all glass compositions after $24 \mathrm{~h}$ immersion in SBF, which was the time point at which HCA was first detected for BG.

smaller particle size range than $\mathrm{NB}$, nucleated more $\mathrm{HCA}$ an earlier time point than NB. The time at which HCA was found on the surface of the different glasses using FTIR and XRD was consistent among the participants. BG and TG were found to be the faster to nucleate HCA, in $24 \mathrm{~h}$, followed by Sr-BG, NB and BA, in 72 h. 13-93 was the slowest with a nucleation time of 1 week. Nucleation of HCA on the 13-93 powder occurred 1 week earlier in the TC04 tests than in the ISO standard. However, the time points were discrete and 1 week apart, as the surface analysis used here was not continuous. This study therefore also highlights the importance of using ICP analysis to study dissolution and apatite formation of bioactive glasses. The change in phosphate concentration as a function of time can give a more accurate information on the precipitation of calcium phosphate. The time point where phosphate concentration drops 

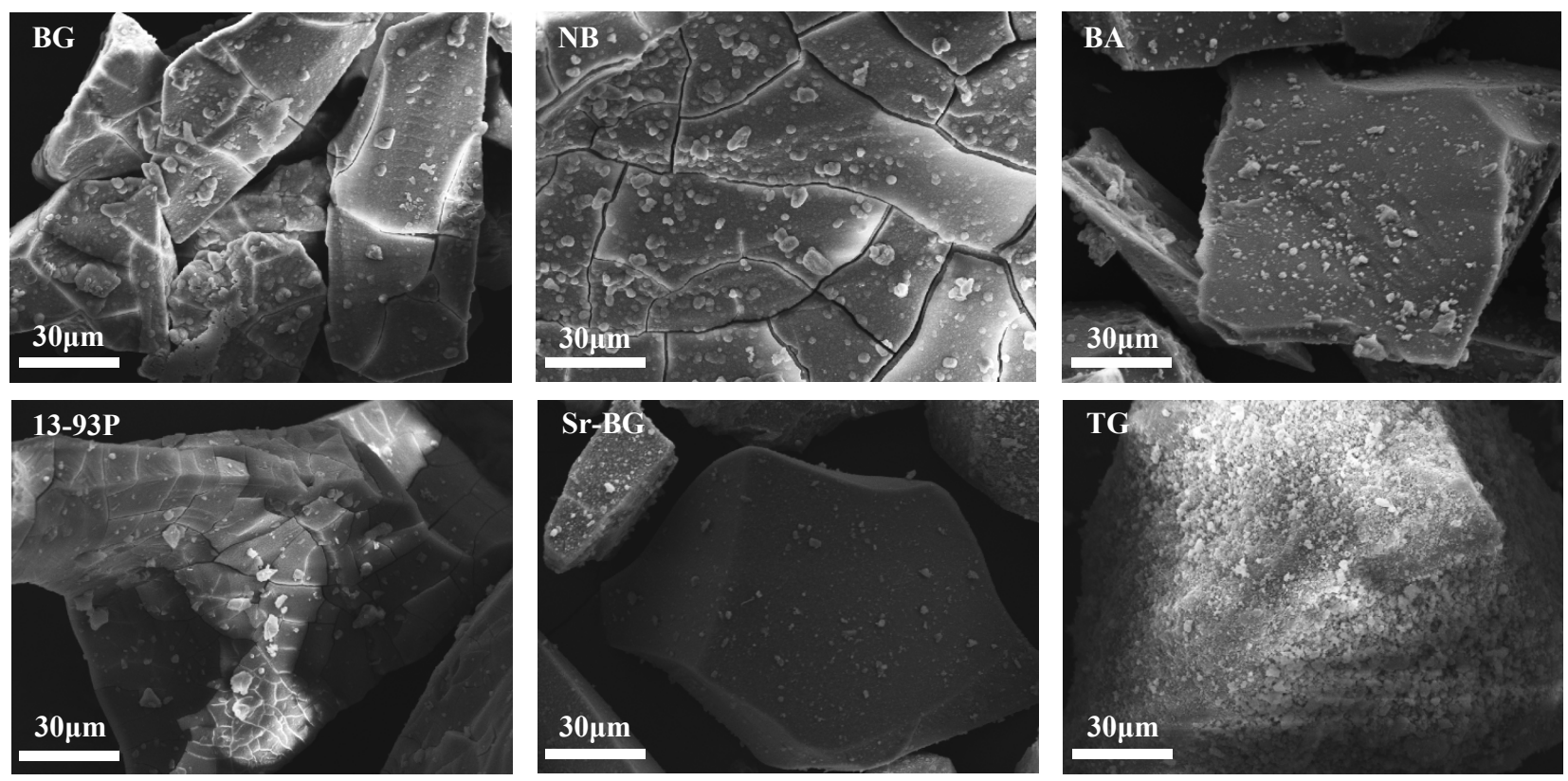

Fig. 4 SEM micrographs of bioactive glasses immersed in SBF for 24h by the TC04 method.

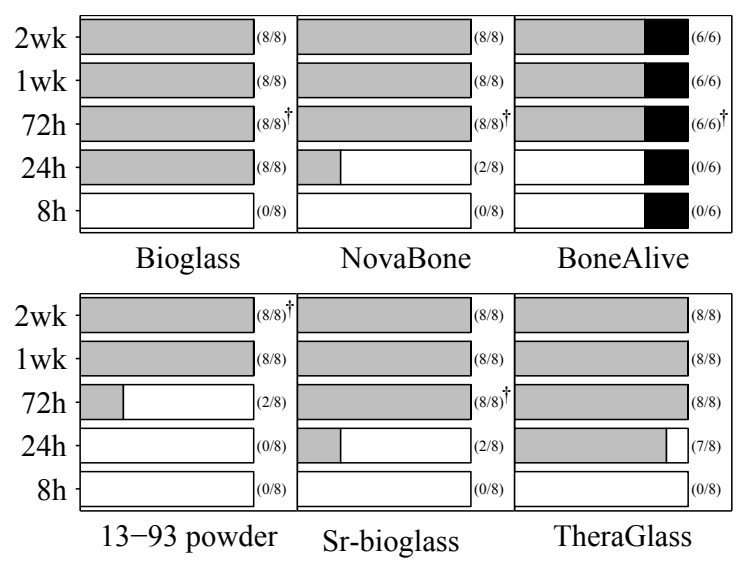

Fig. 5 Histograms representing the time at which HA was revealed by FTIR and XRD by the 8 different institutions that participated to this round robin. ${ }^{\dagger}$ indicates the nucleation time using the ISO standard. Only 6 out of 8 laboratories run BonAlive. Due to its high surface area $\left(\approx 80 \mathrm{~m}^{2} \cdot \mathrm{g}^{-1}\right)$, TG was not tested using the ISO method

rapidly can be correlated to calcium phosphate precipitation on the glass surface. ICP can be used to refine the window of time in which HCA formation occurs. HCA formation was different for different glass compositions due to the change in network connectivity (NC) of the glasses[25]. NC increases with increased silica content (e.g. BA compared to $\mathrm{BG}$ ), but also with the introduction of network intermediates. 13-93 contains magnesium, of which a proportion is thought to act as an intermediate, forming -Si-O-Mg-O-Sitype bonding [36]. The TC04 test is a relatively simple test that distinguishes between different glasses and should be employed by groups wanting to test new bioactive glasses, or their variants, which will enable comparison between the literature in the future.

\section{Conclusion}

The aim of this study was to suggest a method for testing bioactive glasses, particularly those of high surface area, and to verify the reproducibility of the method by a large number of research groups working in the field. The protocol was a modified version of the ISO standard for testing apatite formation based on sample mass to liquid ratio. Comparison with the ISO standard showed that the method proposed here was more appropriate for bioactive glasses, particularly for particles or glasses with high surface area.

Acknowledgements The International Commission on Glass is thanked for its support of TC04 and its members. The European Forum of New Glass Application is also thanked for its support. The authors would like to thank Vivoxid (Turku, Finland), Mo-Sci (Rolla, MO), RepRegen Ltd (London, UK) and Novabone LLC (Alachua, FL) for generously providing samples.

\section{References}

1. Hench LL, Splinter RJ, Allen WC, Greenlee TK (1971) Bonding mechanisms at the interface of ceramic prosthetic materials. Journal of Biomedical Materials Research 5:117141 
2. Oonishi H, Hench LL, Wilson J, Sugihara F, Tsuji E, Matsuura M, Kin S, Yamamoto T, Mizokawa S (2000) Quantitative comparison of bone growth behavior in granules of Bioglass ${ }^{\circledR}, \mathrm{A}-\mathrm{W}$ glass-ceramic, and hydroxyapatite. Journal of Biomedical Materials Research 51:3746

3. Ślośarczyk A, Paszkiewicza Z, Paluszkiewicz C (2005) FTIR and XRD evaluation of carbonated hydroxyapatite powders synthesized by wet methods. Journal of Molecular Structure 744-747:657-661

4. Cerruti M, Greenspan D, Powers K (2005) Effect of pH and ionic strength on the reactivity of Bioglass ${ }^{\circledR}$ 45S5. Biomaterials 26:1665-1674

5. Du MQ, Bian Z, Jiang H, Greenspan DC, Burwell AK, Zhong J, Tai BJ (2008) Clinical evaluation of a dentifrice containing calcium sodium phosphosilicate (novamin) for the treatment of dentin hypersensitivity. American Journal of Dentistry 21:210214

6. Mizuno M (2014) Implants for surgery - In vitro evaluation for apatite-forming ability of implant materials. ISO ISO/DIS 23317, International Organization for Standardization, Geneva, Switzerland

7. Fu Q, Rahaman MN, Bal BS, Brown RF, Day DE (2008) Mechanical and in vitro performance of 13-93 bioactive glass scaffolds prepared by a polymer foam replication technique. Acta Biomaterialia 4:1854-1864

8. Quintero F, Pou J, Comensa R, Lusquinos F, Riveiro A, Mann AB, Hill RG, Wu ZY, Jones JR (2009) Laser spinning of bioactive glass nanofibers. Advanced Functional Materials 19:3084-3090

9. Brown RF, Day DE, Day TE, Jung S, Rahaman MN, $\mathrm{Fu} Q$ Growth and differentiation of osteoblastic cells on 13-93 bioactive glass fibers and scaffolds

10. Jones JR, Ehrenfried LM, Hench LL (2006) Optimising bioactive glass scaffolds for bone tissue engineering. Biomaterials 27:964-973

11. Bohner M, Lemaitre J (2009) Can bioactivity be tested in vitro with SBF solution? Biomaterials 30:2175-2179

12. kokubo T, Kushitani H, Sakka S, Kitsugi T, Yamamoto $\mathrm{T}$ (1990) Solutions able to reproduce in vivo surfacestructure changes in bioactive glass-ceramic A-W. Journal of Biomedical Material Research 24:721-734

13. O'Donnell MD (2011) Predicting bioactive glass properties from the molecular chemical composition: Glass transition temperature. Acta Biomaterialia 7:22642269

14. Brink M, Turunen T, Happonen RP, Yli-Urpo A (2011) Compositional dependence of bioactivity of glasses in the system $\mathrm{Na}_{2} \mathrm{O}-\mathrm{K}_{2} \mathrm{O}-\mathrm{MgO}-\mathrm{CaO}-\mathrm{B}_{2} \mathrm{O}_{3}-\mathrm{P}_{2} \mathrm{O}_{5}-\mathrm{SiO}_{2}$. Acta Biomaterialia 7:2264-2269

15. O’Donnell MD, Candarlioglu PL, Miller CA, Gentleman E, Stevens MM (2010) Materials characterisation and cytotoxic assessment of strontium-substituted bioactive glasses for bone regeneration. Journal of Materials Chemistry 20:8934-8941

16. Saravanapavan P, Hench LL (2000) Low-temperature synthesis, structure, and bioactivity of gel-derived glasses in the binary $\mathrm{CaO}-\mathrm{SiO}_{2}$ system. Journal of Biomedical Materials Research 54:608-618

17. Brunauer S, Emmett PH, Teller E (1938) Adsorption of Gasses in Multimolecular Layers. Journal of the American Chemical Society 60:309-319

18. Jones JR, Sepulveda P, Hench LL (2001) DoseDependent Behavior of Bioactive Glass Dissolution. Journal of Biomedical Materials Research 58:720-726

19. Allen T (1997) Particle Size Measurement: Volume 2: Surface Area and Pore Size Determination. Kluwer Academic Publishers

20. Lin S, Ionescu C, Pike KJ, Smith ME, Jones JR (2009) Nanostructure evolution and calcium distribution in solgel derived bioactive glass. Journal of Materials Chemistry 19:1276-7282

21. Lowell S, Shields JE, Thomas MA, Thommes M (2004) Characterization of porous solids and powders: Surface area, pore size and density. Springer

22. Sing KSW (1985) Reporting physisorption data for gas/solid systems with special reference to the determination of surface area and porosity. Pure and Applied Chemistry 57:603-619

23. Sepulveda P, Jones JR, Hench LL (2002) In vitro dissolution of melt-derived 45S5 and sol-gel derived 58S bioactive glasses. Journal of Biomedical Materials Research 61:301-311

24. Arcos D, Vallet-Regí M (2010) Sol-gel silica-based biomaterials and bone tissue regeneration. Acta Biomaterialia 6:2876-2888

25. Jones JR (2013) Review of bioactive glass: From Hench to hybrids. Acta Biomaterialia 9:4457-4486

26. Rámila A, Vallet-Regí M (2001) Static and dynamic in vitro study of a sol-gel glass bioactivity. Biomaterials 22:2301-2306

27. Oliveira JM, Correia RN, Fernandes M (2002) Effects of Si speciation on the in vitro bioactivity of glasses. Biomaterials 23:371379

28. Li P, Ohtsuki C, Kokubo T, Soga N, de Groot K (1994) The role of hydradted silica, titania and alumina in inducing apatite on implants. Journal of Biomedical Materials Research 28:7-15

29. Raynaud S, Champion E, Bernache-Assollant D, Thomas P (2002) Calcium phosphate apatites with variable $\mathrm{Ca} / \mathrm{P}$ atomic ratio I. Synthesis, characterisation and thermal stability of powders. Biomaterials 23:10651072

30. Stocha A, bskia WJ, Brozeka A, Stochb J, Szaranieca J, Trybalskaa B, Kmita G (2000) FTIR absorptionreflection study of biomimetic growth of phosphates on titanium implants. Journal of Molecular Structure 
555:375382

31. Mùller L, Mùller FA (2006) Preparation of SBF with different $\mathrm{HCO}_{3}^{-}$content and its influence on the composition of biomimetic apatites. Acta Biomaterialia 2:181-189

32. Elliot JC, editor (1994) Structure and chemistry of the apatites and other calcium orthophosphates. Amsterdam: Elsevier Science

33. Gisbon IR, Rehman I, Best SM, Bonfield W (2000) Characterization of the transformation from calciumdeficient apatite to $\beta$-tricalcium phosphate. Journal of Materials Science: Materials in Medicine 12:799-804

34. Martínez A, Izquierdo-Barba I, Vallet-Regí M (2000) Bioactivity of a $\mathrm{CaO}-\mathrm{SiO}_{2}$ Binary Glasses System. Chemistry of Materials 12:3080-3088

35. Jalota S, Bhaduri SB, Tas AC (2004) Effect of carbonate content and buffer type on calcium phosphate formation in SBF solutions. Journal of Materials Science: Materials in Medicine 17:697-707

36. Watts SJ, Hill RG, O'Donnell MD, Law RV (2010) Influence of magnesia on the structure and properties of bioactive glasses. Journal of Non-Crystalline Solids 356:517-524 